\title{
Pedestrian and bike path illumination for safety and security: empirical pre- and post-field studies by a university team
}

\author{
P. Hebert ${ }^{1}$, T. Sammons ${ }^{2}$, M. Kang ${ }^{1}$ \& H.-J. Lee ${ }^{1}$ \\ ${ }^{1}$ Department of Design, Housing and Merchandising, \\ Oklahoma State University, USA \\ ${ }^{2}$ School of Architecture and Design, \\ University of Louisiana at Lafayette, USA
}

\begin{abstract}
A lighting design solution for a proposed, two mile long, pedestrian and bike path was developed. The path, with sections both near to and distant from the roadway, bordered a University campus in the southern US and served to link existing University buildings, a University/community arena and parking. In 2005, research team members examined existing lighting conditions. The team considered existing spill lighting from nearby buildings and roadways. Following industry procedures, they took sample light meter readings utilizing a hand-held lux meter. After a five year delay in Federal funding, construction on the illuminated pedestrian and bike path project commenced. The bike path project, including the installation of high pressure sodium illumination by acorn head pole fixtures, was accepted by Federal and University officials. Immediately after the path's completion in 2012, the researchers re-measured light levels at the site. They compared their pre- and post-installation measurements to the industry recommendations in effect during these two time periods. The researchers also used a digital sky quality meter to determine light pollution in the vicinity of the path. The path is currently in use by the University and community stakeholders.

Keywords: pedestrian path, bike path, lighting, community, field study, safety, security, outdoor, USA.
\end{abstract}




\section{Introduction}

A bike path is a separate facility, which is exclusively used for bicyclists or shared by bicyclists with other non-motorized traffic. It is usually narrower than a roadway [1]. Although findings from previous studies are somewhat mixed, in general, people prefer riding a bicycle on bike paths to cycling in mixed traffic $[1,2]$. This may be because people think riding a bicycle on bike paths is much safer than riding a bicycle on roadways without such paths. In fact, previous studies reported that crash rates were lower when riding on bike paths than when sharing a roadway with motorized vehicles [3, 4]. The considerable amount of attention that has been brought to bicycling safety has discouraged people from riding bicycles [5, 6]. According to the National Survey of Pedestrian and Bicyclist Attitudes and Behaviors [7], more than 13\% of people reported they felt unsafe while bicycling mainly due to motorists, followed by uneven walkways or roadways, dogs and other animals, and potential for crime. Therefore, to encourage people in the US to ride bicycles more often and to use bicycles for everyday travel, it is imperative to provide supportive environments such as bike paths. Supplying these paths with recommended lighting illumination will increase safety during hours of darkness thereby encouraging more frequent use.

Proper lighting may help to ensure the safety of pedestrian and bicyclists, as the night time environment may be more threatening or present more risks than the daytime environment. This study focused on pedestrian and bike path illumination. The purpose of this study was to examine lighting conditions at a recently completed bike path by conducting field measurements of existing illumination at night and comparing them to industry recommendations, the Illuminating Engineering Society of North America (IESNA) lighting recommendations for pedestrian and bike paths. The measurements were gathered in two evening sessions, before and after the new lighting installation. The objectives of the study included 1) determine and document lighting conditions in an area chosen for a new bike path before and after path construction and new lighting installation and 2) compare findings to industry recommendations, the IESNA lighting recommendations for pedestrian and bike paths.

\section{Pedestrian and bike path illumination}

Bicyclists incur a higher number of injuries requiring hospitalization than do motor vehicle occupants; therefore, understanding ways of making bicycling safer is important to increasing rates of bicycling and improving population health. Reynolds et al. [8] suggested that infrastructure influences injury and crash risk. They showed that purpose-built bicycle-specific facilities may reduce crashes and injuries among cyclists. Spaces which are poorly illuminated and used after dark increase the likelihood of accidents and invite crime. Kim et al. [9] conducted a study to determine the factors contributing to the injury severity of bicyclists in bicycle-motor vehicle accidents. Darkness in the absence 
of streetlights was one of factor which more than doubled the probability of a bicyclist suffering a fatal injury in an accident. The correct lamps (light bulbs), appropriate lighting fixtures, proper maintenance, and lighting design that follow the IESNA's Guideline for Security Lighting for People, Property, and Public Spaces resulted in feelings of safety [10]. Willis et al. [11] investigated the benefits of improved streetlights, associated with the replacement of lowpressure sodium streetlights with high-pressure sodium streetlights. Highpressure sodium offers higher Color Rendering Indices (CRI) than low-pressure sodium. In Willis et al.'s study [11], improved street lighting provided higher luminosity, improved color rendition of outdoor objects and created less light pollution. Other benefits included reductions in crime and road accidents, streetscape enhancements and increased amenity attributable to less light pollution.

Appropriately illuminated bike paths offer increased safety and allow for longer use of paths after dusk. When installing lighting in a multipurpose, heavily used corridor, which pedestrians and bicyclists utilize every day, light pollution needs to be considered. The problem of light pollution affects local residents who do not want light shining into their back yards during all hours of the night. Immediately adjacent residents might not be supportive of a bike path light installation. Hesselberg [12] described a case where bike path users and surrounding residents debated the issues of a lighting installation on the competing intents of increasing safety and decreasing light trespass. The city decided to implement a lighting fixture that, if installed, would channel light downwards rather than outwards by way of a louvered lamp shade. The International Dark Sky Association (IDA) recommends the use of cutoff fixtures, with no uplight to mitigate light pollution and light trespass [13].

\section{Method}

Twenty students and four faculty team members actively participated in this pedestrian and bike path project over time. The team considered industry recommendations and measured illuminances for pre- and post-installation conditions. The data were analyzed utilizing descriptive statistics. Various software programs, including AutoCAD, Excel, Word, and Photoshop, were utilized to propose new lighting.

In 2005, team members examined existing lighting conditions along the two mile length of a proposed new pedestrian and bike path. The path was intended to link the edges of an existing University campus with the University's growing research park. Parts of the proposed path were adjacent to existing roadways and parking lots (see Figures 1 and 2). Several large, existing buildings frequented by the local community were situated along the proposed path; residential areas were also located nearby but not adjacent.

Following industry procedures, the researchers sampled light levels along the proposed pathway utilizing a hand-held lux meter (Extech Instruments 403123 meter). Since path lighting was not yet installed, researchers considered current spill lighting contributions along the proposed path from existing pole mounted 


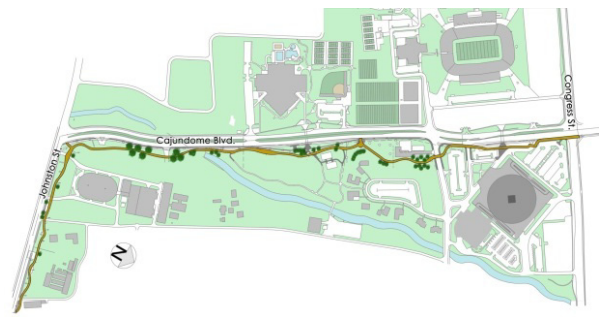

Figure 1: Map of the proposed two mile pedestrian and bike path project. Courtesy of University of Louisiana at Lafayette, Community Design Workshop.

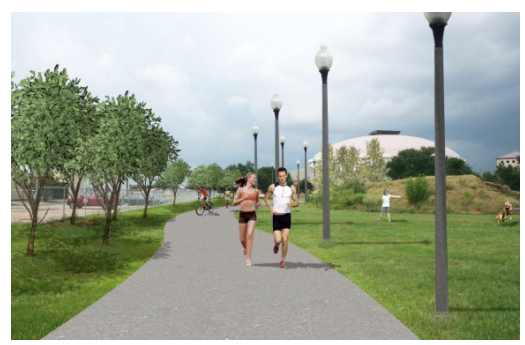

Figure 2: Rendering of proposed pedestrian and bike path. Courtesy of University of Louisiana at Lafayette, Community Design Workshop.

lights, building mounted lights from nearby structures, and light fixtures illuminating existing minor sidewalks and adjacent roadways. The collected lighting data were utilized by a larger design team to develop a lighting design solution which was accepted by the University, the community and the Federal funding agency.

Later in 2005, a catastrophic natural disaster, Hurricane Katrina, occurred in the southern US state where the project was located. The extensive and costly recovery that followed pre-empted the available Federal funding for construction projects in the state. Construction on the proposed, illuminated pedestrian and bike path project was delayed. Five years later when monies were again available, the project was resurrected and the installation commenced. A total of 179 nostalgic style, acorn-shaped fixtures, lamped with 100 watt high-pressure sodium lamps and mounted on 9'-6" poles, were installed along the new pedestrian and bike path (see Figure 3 ). The pedestrian and bike path project garnered public interest, and several print articles appeared in local media which documented the project's process, progress and perceptions. 
Immediately after the path's completion in 2012, the researchers re-measured the lighting at the pedestrian and bike path site utilizing a hand-held lux meter (Extech Instruments 403123 meter). The bike path pavement was visually matched to a Light Reflectance Value (LRV) chart found in a commercial paint selector deck. The researchers also used a digital sky quality meter (Unihedron SQM) to measure sky quality to determine light pollution levels in the vicinity of the path in mags/arcsecond ${ }^{2}$.

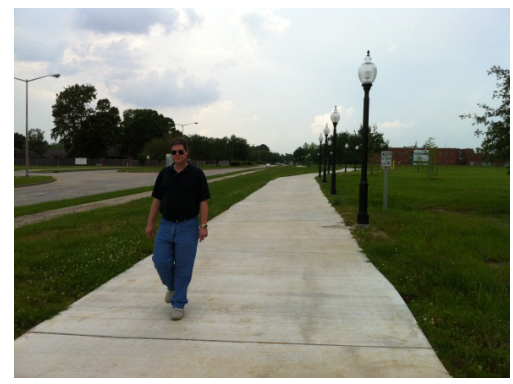

Figure 3: Post-installation view of pedestrian and bike path with acorn-style pole fixtures and pavement surface LRV of $39 \%$.

\section{Results}

\subsection{Industry recommendation changes}

The researchers found the IESNA's lighting recommendations for pedestrian and bike paths have changed over time (see Tables 1 and 2). Lighting level recommendations in 2000 were found to be more prescriptive whereas 2011 recommendations advocated a more custom approach with the consideration of many variables $[14,15]$. Additionally, the recommended measurement height for vertical light levels and the overall vertical measurement procedures were modified during the bike path project's timeframe. Generally the light level recommendations have decreased over time. Also, the 2000 recommended singular measurement protocol at 1.83 meters (6’-0”) height was changed to a recommendation of dual opposing planes measurements at 1.53 meters (5'-0”) height in 2011. The latter was intended to more accurately account for the illumination of the faces of pedestrians and bicyclists.

Standard measurements for sky quality are relatively new. As recent as 2005, relatively inexpensive sky quality meters were in common use. Some were distributed to lighting educators who were interested in light pollution assessment. A lower measurement (roughly 19, mags/arseconds ${ }^{2}$ or lower) is considered evidence of light pollution. 
Table 1: $\quad$ Recommended illuminance for pedestrian and bikeways.

\begin{tabular}{|c|c|c|c|c|}
\hline \multicolumn{3}{|c|}{ ILLUMINATING ENGINEERING SOCIETY(IES) 2000} & \multicolumn{2}{|c|}{ IES 2011} \\
\hline HORIZONTAL & LUX (LX) & $\begin{array}{l}\text { FOOTCANDLES } \\
\text { (FC) }\end{array}$ & LUX (LX) & $\begin{array}{l}\text { FOOTCANDLES } \\
\text { (FC) }\end{array}$ \\
\hline Average - Commercial & $10.00 *$ & $1.00 *$ & NA & NA \\
\hline Average-Intermediate & $5.00-6.00^{*}$ & $0.05-0.06 *$ & $7.80^{*}$ & $0.80^{*}$ \\
\hline Average - Residential & $2.00 *$ & $0.02 *$ & NA & NA \\
\hline $\begin{array}{l}\text { Maximum: Minimum } \\
\text { Uniformity Ratio }\end{array}$ & 10:1 & $10: 1$ & $10: 1$ & $10: 1$ \\
\hline $\begin{array}{l}\text { Average: Minimum } \\
\text { Uniformity Ratio }\end{array}$ & $4: 1-10: 1$ & $4: 1-10: 1$ & $4: 1$ & $4: 1$ \\
\hline \multicolumn{5}{|l|}{ VERTICAL } \\
\hline Average-Commercial & $22.00 * * *$ & $2.20^{* * *}$ & NA & NA \\
\hline Average-Intermediate & $11.00 * * *$ & $1.10^{* * *}$ & $0.25-8.00 * *$ & $0.03-0.80^{* *}$ \\
\hline Average-Residential & $5.00 * * *$ & $0.50^{* * *}$ & NA & NA \\
\hline \multicolumn{5}{|l|}{ CONSIDERATIONS $* * * *$} \\
\hline Activities and tasks & & + & & + \\
\hline Surface reflectances & & + & & + \\
\hline Photopic vision & & + & & + \\
\hline Uniformities & & + & & + \\
\hline Scotopic vision & & + & & + \\
\hline Observers usual age & & 0 & & + \\
\hline Activity level & & 0 & & + \\
\hline $\begin{array}{l}\text { Night time ambient lighting } \\
\text { zone }\end{array}$ & & 0 & & + \\
\hline Mesopic vision & & + & & + \\
\hline $\begin{array}{l}\text { Mesopic adaption for high } \\
\text { pressure sodium lighting }\end{array}$ & & 0 & & + \\
\hline Road adjacency & & + & & + \\
\hline $\begin{array}{l}\text { Light trespass and light } \\
\text { pollution }\end{array}$ & & + & & + \\
\hline Color appearance & & + & & + \\
\hline $\begin{array}{l}\text { Modeling of faces and } \\
\text { objects }\end{array}$ & & + & & + \\
\hline
\end{tabular}

NA: Not Available.

*At grade

**At 5'-0" above grade

***At 6'-0" above grade

**** The IES Lighting Handbooks $[14,15]$ ask designers to consider many criteria before determining the appropriate target light levels for a particular application including: anticipated activities, night time outdoor lighting zone, outdoor activity level, light source, pavement reflectance value and observers' ages.

Note: The IES “orientation” category for "recommended illuminance targets" ranges from 0.5-60 lux (0.5-6 fc) for "visual performance is typically not workrelated but related to dark sedentary social situations, senses of safety and security, and casual circulation based on landscape, hardscape, architecture, and people as visual tasks” ([15] p. 4.33). 
Table 2: $\quad$ Measured illuminance for pedestrian and bike path.

\begin{tabular}{|l|l|l|l|l|}
\hline \multicolumn{3}{|c|}{ PRE-INSTALLATION (2005) } & \multicolumn{2}{c|}{$\begin{array}{c}\text { POST INSTALLATION } \\
\text { (2012) }\end{array}$} \\
\hline HORIZONTAL & LUX (LX) & $\begin{array}{c}\text { FOOTCANDLES } \\
\text { (FC) }\end{array}$ & LUX (LX) & $\begin{array}{c}\text { FOOTCANDLES } \\
\text { (FC) }\end{array}$ \\
\hline Minimum & $1.08^{*}$ & $0.01^{*}$ & $3.34^{*}$ & $0.31^{*}$ \\
\hline Maximum & $77.61^{*}$ & $7.21^{*}$ & $33.91^{*}$ & $3.16^{*}$ \\
\hline Mean & $4.84^{*}$ & $0.45^{*}$ & $17.11^{*}$ & $1.59^{*}$ \\
\hline $\begin{array}{l}\text { Maximum: Minimum } \\
\text { Uniformity Ratio }\end{array}$ & $72: 1$ & $72: 1$ & $10: 1$ & $10: 1$ \\
\hline $\begin{array}{l}\text { Average: Minimum } \\
\text { Uniformity Ratio }\end{array}$ & $4.5: 1$ & $4.5: 1$ & $5: 1$ & $5: 1$ \\
\hline VERTICAL & & & & \\
\hline Minimum & NA & NA & $5.27^{* *}$ & $0.49^{* *}$ \\
\hline Maximum & NA & NA & $41.12^{* *}$ & $3.82^{* *}$ \\
\hline Mean & NA & NA & $24.33^{* *}$ & $2.26^{* *}$ \\
\hline $\begin{array}{l}\text { Maximum: Minimum } \\
\text { Uniformity Ratio }\end{array}$ & NA & NA & $8: 1$ & $8: 1$ \\
\hline
\end{tabular}

NA: Not Available.

*At grade.

**At 1.52 meters (5’-0”) above grade.

\subsection{Calculating target illuminances}

The researchers utilized the steps indicated in the current, 2011 IESNA recommendations ([15] p. 12.26), and referred to the associated tables to recreate the current target illuminance recommendations utilized for this pedestrian bike path. First the researchers established a "nighttime outdoor lighting zone". Based on their field observations of the bike path's conditions, the researchers selected "LZ3," "moderately high ambient lighting”, with "areas of human activity where the vision of human residents and users is adapted to moderately high light levels" where "lighting is generally desired for safety, security and/or convenience and it is often uniform..." Next, the researchers established the "activity level" as "outdoor medium" which includes "areas with relatively moderate volumes of pedestrians and vehicles or solely people during dark hours..." Based on field observations, the researcher then selected the: "25 to 65 visual ages of observers (years) where at least half' are this age. They additionally selected the category "slow-to-moderate-paced situations". After also considering that the stakeholders were especially interested in facial recognition, safety and security along the path, the selected parameters led researchers to establish the photopic illuminance criteria of: 6 lux (0.56 footcandles) "horizontal" and 2 lux (0.19 footcandles) "vertical". Then the researchers "estimated surface reflectances", the reflectance values of the surface of the path (39\%) and the surroundings (39\% - 5\%). Of special consideration was the installed high efficacy light source, high-pressure sodium, which had 
been chosen for the pedestrian and bike path installation in the current. High pressure sodium lighting has implications for mesopic adaption. The IESNSrecommended mesopic adaption multiplier of 1.3 was applied. Therefore, using current recommendations the adjusted horizontal illuminance target for this pedestrian and bike path project was determined by researchers to be 7.8 lux (.80 footcandles), and the adjusted vertical illuminance target was set at 2.6 lux (0.24 footcandles).

\subsection{5 in-situ measurements}

In-situ, 660 individual light meter readings of existing illuminance were taken at night. The maximum horizontal light level was found to be 77.61 lux (7.21 fc). The minimum horizontal level was 1.08 lux $(0.01 \mathrm{fc})$. The mean was 4.84 lux $(0.45 \mathrm{fc})$. The maximum to minimum uniformity ratio in the horizontal plane was found to be 72:1. No vertical light levels were taken.

\subsection{2 in-situ measurements}

After the lighting was installed along the path in 2012, a sample of 130 horizontal and vertical footcandle measurements were taken. The maximum horizontal light level was measured to be 33.91 lux (3.15fc). The minimum horizontal light level was found to be 3.34 lux (0.31fc). The mean was 1.76 lux (1.65 fc). The maximum to minimum uniformity ratio in the horizontal plane was 10.15 to 1 . The maximum vertical light level was 41.12 lux (3.82 fc). The minimum vertical light level was 5.27 lux (0.49 fc). The mean was 24.33 lux $(2.26 \mathrm{fc})$. The maximum to minimum uniformity ratio in the vertical plane was 7.80:1. Table 3 shows the comparison of light level recommendations to measurements.

Table 3: Comparison of light level recommendations to measurements.

\begin{tabular}{|c|c|c|c|c|c|c|}
\hline \multicolumn{3}{|c|}{ RECOMMENDATIONS (2000) } & \multicolumn{2}{|c|}{ MEASUREMENTS (2012) } & \multicolumn{2}{|c|}{$\begin{array}{c}\text { RECOMMENDATIONS } \\
(\mathbf{2 0 1 1 )} \\
\end{array}$} \\
\hline HORIZONTAL & LUX (LX) & $\begin{array}{l}\text { FOOT- } \\
\text { CANDLES } \\
\text { (FC) }\end{array}$ & LUX (LX) & $\begin{array}{c}\text { FOOT- } \\
\text { CANDLES (FC) }\end{array}$ & LUX (LX) & $\begin{array}{c}\text { FOOT- } \\
\text { CANDLES (FC) }\end{array}$ \\
\hline Average & $10.00^{*}$ & $1.00 *$ & $17.11^{*}$ & $1.59 *$ & $7.80 *$ & $0.80 *$ \\
\hline $\begin{array}{l}\text { Maximum: } \\
\text { Minimum } \\
\text { Uniformity Ratio }\end{array}$ & $10: 1$ & $10: 1$ & $10: 1$ & $10: 1$ & $10: 1$ & $10: 1$ \\
\hline $\begin{array}{l}\text { Average: minimum } \\
\text { Uniformity Ratio }\end{array}$ & $4: 1-10: 1$ & $4: 1-10: 1$ & $5: 1$ & $5: 1$ & $4: 1$ & $4: 1$ \\
\hline \multicolumn{7}{|l|}{ VERTICAL } \\
\hline Average & $22.00 * * *$ & $2.20 * * *$ & $24.33^{* *}$ & $2.26 * *$ & $2.6^{* *}$ & $0.24 * *$ \\
\hline $\begin{array}{l}\text { Maximum: } \\
\text { Minimum } \\
\text { Uniformity Ratio }\end{array}$ & NA & NA & $8: 1$ & $8: 1$ & NA & NA \\
\hline
\end{tabular}

NA: Not Available.

*At grade.

**At 5'-0" above grade.

***At 6'-0" above grade. 


\subsection{Sky quality meter levels}

SQM levels were taken at six points approximately equidistant along the pedestrian and bike path. The minimum SQM level was found to be 11.3 mags/arcsecond ${ }^{2}$ and the maximum was 15.3 mags/arcsecond ${ }^{2}$. The SQM mean measurement at the site was 14.74 mags/arcsecond ${ }^{2}$. It was determined that the LRV of the path pavement was approximately $39 \%$.

\section{Discussion and conclusions}

Even illumination and low uniformity ratios are important for good visibility along pedestrian and bike paths. Existing light levels measured in-situ in 2005, prior to the path construction and the new lighting installation, were found to be very uneven with a maximum to minimum uniformity ratio of 72:1. This greatly exceeded the 10:1 uniformity ratio recommendations of both 2000 and 2011 . The 2005 light level mean of 4.84 lux was less than $50 \%$ of the 2000 recommendation of 10 lux. The 2005 light level mean was 62\% of the 2011 recommended 7.8 lux average. Vertical light levels were not recorded in 2005.

Light levels measured in-situ in 2012, after the new lighting was installed, were found to be much more even. At 10:1, the uniformity ratio complied with both the 2000 and the 2011 IESNA recommendations. This compliance was anticipated to increase visibility and potentially aid safety and security. The 17.11 horizontal lux average measurement exceeded both the 2000 recommendation of 10 lux (70\% over recommended) as well as the 2011 recommendation of 7.8 lux (200\% over recommended). The 24.33 vertical lux average measurement was more than $11 \%$ over the 2000 recommendation of 22 lux but was $900 \%$ over the 2011 recommendation of 2.6 lux. In later standards books, industry recommendations became more customized and many more variables were considered. Generally, the light level recommendations from 2011 [15] were found to be lower than those recommended in 2000 [14]. The recommended method for taking vertical measurements was changed such that heights above grade were reduced from 6'-0" to 5'-0", one foot further away from the light source in 2011 as compared to 2000. However, the 2000 recommendations differentiated between residential, intermediate and commercial pedestrian and bike paths. Other changes in the decade spanning the release of the two industry lighting recommendations indicated that universities may have become more concerned about safety and security along pedestrian and bike paths and may equate higher light levels with more safety and security. Some may equate overage with waste while others may see increased light levels as insurance against accidents and crime.

In the case of the current project, the majority of university student users may be less than 25 years of age. However, many other university and community stakeholders who use the pedestrian and bike path are older. Also, the 39\% LRV of the path's pavement was determined to be much lighter than the $0 \%, 5 \%$ and $10 \%$ standard choices shown in the IES recommendations worksheet [15]. However, there was no exacting method to acquire a credit for the higher 
reflectance value paving used. In some cases, universities as well as other stakeholders may elect to exceed industry recommendations. They may choose lighting that they believe to be aesthetic and/or to promote higher levels of safety and security.

Although acceptable to the University and to the Federal funding agency, the selected new, acorn globe light fixtures produce considerable vertical illumination and uplight. This light distribution is contrary to that recommended by the IDA. Relatively poor sky was found at the pedestrian and bike path, as indicated by the low SQM readings, 11.3 to 15.3 mags/arcsecond ${ }^{2}$. Some sites in less light polluted skies have been measured as 20 to 21 mags/arcsecond ${ }^{2}$. The lighting levels measured in the 2005 study included spill light from aging lighting systems. However, lighting levels measured in 2012 were initial levels produced by a new lighting system. These levels will decrease over time, dropping closer to the recommended levels. It is also important to note that published industry recommended lighting levels are designed to be maintained rather than initial levels. When lighting installations are new, they are at their peak condition - new, very clean lamps and fixtures free from damage and other problems plaguing older systems.

\section{References}

[1] Hunt, J.D. and Abraham, J.E., Influences on bicycle use. Transportation 34(4), pp. 453-470, 2007.

[2] Antonakos, C. L., Environmental and travel preferences of cyclists. Transportation Research Record, 1438, pp. 25-33, 1994.

[3] Moritz, W.E., Adult bicyclists in the United States: Characteristics and riding experience in 1996. Transportation Research Record, 1636, pp. 1-7, 1998.

[4] Rogers, G.B., Factors associated with the crash risk of adult bicyclists. Journal of Safety Research, 28(4), pp. 233-241, 1997.

[5] Forester, J., The bicycle transportation controversy. Transportation Quarterly, 55(2), pp. 7-17, 2001.

[6] Pucher, J. and Dijkstra, L., Promoting safe walking and cycling to improve public health: Lessons from the Netherlands and Germany. American Journal of Public Health, 93(9), pp. 1509-1516, 2003.

[7] National Highway Traffic Safety Administration (NHTSA), National Survey of Pedestrian and Bicyclist Attitudes and Behaviors, U.S. Department of Transportation: Washington, DC, 2003.

[8] Reynolds, C.C.O., Harris, M.A., Teschke, K., Cripton, P.A. and Winters, M., The impact of transportation infrastructure on bicycling injuries and crashes: A review of the literature. Environmental Health, 8(1), p. 47, 2009. Retrieved from the National Center for Biotechnology.

[9] Kim, J., Kim, S., Ulfarsson, G.F. and Porrello, L.A., Bicyclist injury severities in bicycle-motor vehicle accidents. Accident Analysis and Prevention, 39(2), pp. 238-251, 2007. Retrieved from ScienceDirect database. 
[10] Madsen, J.J., Exterior lighting for safety and security. Buildings, 100(5), p. 80, 2006.

[11] Willis, K.G., Powe, N.A. and Garrod, G.D., Estimating the value of improved street lighting: A factor analytical discrete choice approach. Urban Studies, 42(12), pp. 2289-2303, 2005. Retrieved from the Sagejournals database.

[12] Hesselberg, G., City considers shedding some light on bike path; A newly designed fixture shines only down, not out, but many property owners continue to oppose the idea. The Capital Times and Wisconsin State Journal, p. A1, July 2012.

[13] International Dark Sky Association (IDA). Information Sheet \#30: Discussion of Good Lighting Fixtures, http://www.darksky.org/ assets/documents/is 030.pdf

[14] Rea, M.S. (eds). The lighting handbook (9th Edition), Illuminating Engineering Society of North America: New York, NY, p. 22-11, 2000.

[15] DiLaura, D.L., Houser, K.W., Mistrick, R.G. and Steffy, G.R., (eds). The lighting handbook (10 ${ }^{\text {th }}$ Edition), Illuminating Engineering Society of North America: New York, NY, pp. 2.14-12.27, 2011. 